\title{
Correlation Between Vital Signs and Amount of Hemoperitoneum in Ruptured Ectopic Pregnancy
}

\author{
Puja Baniya Chhetri,' Priya Pathak, ${ }^{2}$ Buddhi Kumar Shrestha,' Rubina Shrestha, ${ }^{1}$ Manisha Acharya,' Subha Shrestha' \\ 'Department of Obstetrics and Gynecology, College of Medical Sciences, Chitwan, Nepal ${ }^{2}$ Department of Community Medicine, \\ College of Medical Sciences, Chitwan, Nepal
}

\section{ABSTRACT}

\section{Introduction}

Ectopic pregnancy is a life threatening emergency in first trimester of pregnancy. Hemodynamic stability of the patient remains one of the crucial factors that determine the treatment modalities. The main objective of this study was to study the correlation between the vital signs and amount of hemoperitoneum in ruptured ectopic pregnancy so that early and active interventions can be done.

\section{Methods}

We conducted a cross sectional study of all the pregnant women with ruptured ectopic pregnancy with hemoperitoneum who presented to the emergency department of College of Medical Sciences Teaching Hospital from time period of $1^{\text {st }}$ May 2017-31 ${ }^{\text {st }}$ May 2020.The different vital signs present at the time of initial emergency department and preoperative period prior surgery were reviewed and used for correlation with amount of hemoperitoneum by using Pearson correlation analysis.

\section{Results}

A total of 61 patients were studied. Pearson correlation between different vital signs and amount of hemoperitoneum were: heart rate $(\mathrm{r}=0.48, \mathrm{p}<0.001)$, systolic blood pressure $(\mathrm{r}=-0.41, \mathrm{p}=0.001)$, diastolic blood pressure $(r=-0.34, p=0.06)$, mean arterial pressure $(r=-0.37, p=0.03)$, respiration rate $(r=0.33, p=0.08)$ temperature $(r=0.09, p=0.94)$, and shock index $(r=0.55, p<0.001)$. Only 19 of 36 patents with hemoperitoneum $\geq 750 \mathrm{ml}$ had $\mathrm{HR} \geq 100$ beats/min and 8 patients had $\mathrm{SBP} \leq 90 \mathrm{mmHg}$.

\section{Conclusion}

None of the vital signs showed strong association with the amount of hemoperitoneum. If decision for surgical interventions were made based on hemodynamic instability, most of the patients would have been over-diagnosed and treated differently. Proper and timely diagnosis with immediate management should be done.

Key words: vital signs; hemoperitoneum; ectopic pregnancy.

Correspondence: Dr. Puja Baniya Chhetri, Department of Obstetrics and Gynecology, College of Medical Sciences, Chitwan, Nepal. Email:pujajgautam@gmail.com, Phone: +977-9841047966. 


\section{INTRODUCTION}

Ectopic pregnancy is the life threatening condition in first trimester of pregnancy accounting $10 \%$ of all maternal pregnancy related deaths. ${ }^{1,2}$ Both the surgical and medical management are present according to the clinical stability of the patient. A hemodynamically stable patient initially undergoes further evaluation whereas unstable patient undergoes emergent surgical intervention. ${ }^{3}$ Tachycardia, tachypnea and hypotension are the initial physiological response to the volume of hemoperitoneum greater than $750 \mathrm{ml}^{4}$ However the clinical stability of the patient with ruptured ectopic pregnancy poorly associates with the amount of ongoing hemoperitoneum. Delay in diagnosis and failure to predict hypovolemia can result in serious maternal morbidity and mortality. ${ }^{5-7}$

This study aimed to find the correlation between the different vital signs and hemoperitoneum in patients with ruptured ectopic pregnancy so that early diagnosis and immediate management can be done as patient may be bleeding internally even with normal vital signs.

\section{METHODS}

We conducted a cross sectional study of all pregnant women with ruptured ectopic pregnancy with hemoperitoneum who presented to emergency department of College of Medical Sciences Teaching Hospital (COMSTH) between time periods of 3 years from $1^{\text {st }}$ May 2017-31 $1^{\text {st }}$ May 2020. Ethical approval was obtained from the Institutional Review Committee of the institute (IRC-COMSTH). All the information were retrieved from the medical records section of the hospital. The pregnant women with postoperative diagnosis of unruptured ectopic pregnancy, with preexisting cardiac diseases and taking any hypertensive and anti-arrhythmic medications were excluded. The heart rate(HR), systolic blood pressure(SBP), diastolic blood pressure(DBP), mean arterial pressure(MAP), temperature(Temp), respiration rate(RR) and shock index(SI) present at the time of initial emergency department and pre-operative interventions in operation room were reviewed and documented. The amount of hemoperitoneum postoperatively was recorded and used as dependent variable and divided into subgroups for correlation analysis. Data input was done by Microsoft excel and analysis by SPSS version 20.0. Descriptive analysis was used to show the distribution of variables. Correlation was seen by Pearson's correlation with Level of significance set at 0.05 .

\section{RESULTS}

A total of 62 pregnant women with diagnosis of ruptured ectopic pregnancy with presence

Table 1. Vital Signs and amount of hemoperitoneum of the patients.

\begin{tabular}{|l|l|l|l|l|}
\hline \multirow{2}{*}{ Parameters } & \multicolumn{2}{c|}{ Mean } & \multicolumn{2}{c|}{ Range } \\
\cline { 2 - 5 } & ED & OR & ED & OR \\
\hline Heart Rate (beats/min) & 94.62 & 89.93 & $62-120$ & $70-120$ \\
\hline Systolic Blood pressure $(\mathrm{mmHg})$ & 105.41 & 110.98 & $60-130$ & $70-130$ \\
\hline Diastolic Blood pressure $(\mathrm{mmHg})$ & 67.05 & 71.64 & $40-90$ & $40-90$ \\
\hline Respiratory Rate (beats/min) & 21.72 & 20.63 & $18-32$ & $18-28$ \\
\hline Temperature ( $\left.{ }^{\circ} \mathrm{F}\right)$ & 97.96 & 98.02 & $97-101$ & $97-99$ \\
\hline Mean Arterial Pressure $(\mathrm{mmHg})$ & 79.98 & 84.26 & $47-103$ & $50-103$ \\
\hline Shock Index & 0.89 & 0.80 & $0.50-2$ & $0.50-1.60$ \\
\hline
\end{tabular}

ED: Emergency department; OR: Operation room; mmHg: Millimeter of Mercury; F: Fahrenheit 
of hemoperitoneum at the time of surgery were identified. One patient had preexisting cardiac diseases and was excluded from the study. The mean age of patients was $28 \pm 5$ years and the age varied between 19 and 40 years. The mean gestational age was $7.1 \pm 2.3$ weeks, with minimum of 3 weeks and maximum of 12 weeks. The mean values and their range of all the recorded vitals were listed in Table 1.

Tachycardia ( $\mathrm{HR} \geq 100$ beats/min) and hypotension (SBP $\leq 90 \mathrm{mmHg}$ ) was present in $23(37.7 \%)$ and 11 $(18.03 \%)$ patients respectively. The mean volume of recorded intraoperative hemoperitoneum was $1116.47 \mathrm{ml}$ with extremes ranging from 3003600 ml.About 36 of 61 patients (59.01\%) had hemoperitoneum $\geq 750 \mathrm{ml}$. Among them only 19 patients had $H R \geq 100$ beats/min and 8 patients had $\mathrm{SBP} \leq 90 \mathrm{mmHg}$. Among 38 patients whohad $\mathrm{HR}<100$ beats/min, 13 patients had hemoperitoneum $\geq 750$ $1500 \mathrm{ml}$ and 5 patients had hemoperitoneum $\geq 1500$ $\mathrm{ml}$. SBP>90mmHg was observed in 50 patients. 26 patients had hemoperitoneum $\geq 750-1500 \mathrm{ml}$ and 6 patients had hemoperitoneum $\geq 1500 \mathrm{ml}$.Only 19 of 36 patients with hemoperitoneum $\geq 750 \mathrm{ml}$ had $\mathrm{HR} \geq 100$ beats/min.

Pearson correlation between different vital signs and amount of hemoperitoneum were: heart rate $(\mathrm{r}=0.48$, $\mathrm{p}<0.001)$, systolic blood pressure $(\mathrm{r}=-0.41, \mathrm{p}=0.001)$, diastolic blood pressure $(\mathrm{r}=-0.34, \mathrm{p}=0.06)$, mean arterial pressure $(\mathrm{r}=-0.37, \mathrm{p}=0.03)$, respiration rate $(\mathrm{r}=0.33, \mathrm{p}=0.08)$ temperature $(\mathrm{r}=0.09, \mathrm{p}=0.94)$, and shock index $(\mathrm{r}=0.55, \mathrm{p}<0.001)$. Patients were further divided into different subgroups according to the volume of the hemoperitoneum. Correlation between vital signs and amount of hemoperitoneum in each group were shown in Table 2 and Table 3.

Table 2. Correlation between vital signs at Emergency department and different amount of hemoperitoneum.

\begin{tabular}{|c|l|l|l|l|c|}
\hline \multirow{4}{*}{ Parameters } & \multicolumn{4}{c|}{ Amount of Hemoperitoneum( $\mathrm{ml}$ ) } \\
\cline { 2 - 6 } & \multicolumn{1}{|c|}{$<750$} & $\geq 750-1500$ & $\geq 1500$ & \multicolumn{1}{c|}{ All } \\
\cline { 2 - 6 } & Heart Rate & $-0.03, p=0.87$ & $0.182, p=0.41$ & $0.57, p=0.04$ & $0.48, p<0.001$ \\
\cline { 2 - 6 } & Systolic Blood Pressure & $-0.14, p=0.48$ & $-0.05, p=0.79$ & $-0.72, p<0.01$ & $-0.41, p=0.01$ \\
\cline { 2 - 6 } $\begin{array}{c}\text { Pearson } \\
\text { Correlation }\end{array}$ & Diastolic Pressure & $-0.15, p=0.47$ & $0.08, p=0.69$ & $-0.63, p=0.19$ & $-0.34, p=0.06$ \\
\cline { 2 - 6 } & Mean Arterial Pressure & $-0.11, p=0.60$ & $0.04, p=0.85$ & $-0.69, p=0.008$ & $-0.37, p=0.03$ \\
\cline { 2 - 6 } & Temperature & $0.28, p=0.18$ & $0.28, p=0.18$ & $-0.08, p=0.72$ & $0.09, p=0.94$ \\
\cline { 2 - 6 } & Shock Index & $0.02, p=0.89$ & $0.19, p=0.38$ & $0.71, p=0.006$ & $0.55, p<0.001$ \\
\cline { 2 - 6 } & Respiratory Rate & $-0.21, p=0.31$ & $0.16, p=0.45$ & $0.60, p=0.03$ & $0.33, p=0.08$ \\
\hline
\end{tabular}

Table 3. Correlation between pre-operative vital signs at Operating room and different amount of hemoperitoneum.

\begin{tabular}{|c|l|c|c|c|c|}
\hline \multirow{2}{*}{ Parameters } & \multicolumn{4}{c|}{ Amount of Hemoperitoneum( $\mathrm{ml}$ ) } \\
\cline { 3 - 6 } & & $<750$ & $\geq 750-1500$ & $\geq 1500$ & \multicolumn{1}{c|}{ All } \\
\cline { 2 - 6 } & Heart Rate & $-0.18, p=0.39$ & $0.31, p=0.15$ & $0.39, p=0.18$ & $0.64, p<0.001$ \\
\cline { 2 - 6 } & Systolic Blood Pressure & $0.10, p=0.61$ & $-0.15, p=0.48$ & $-0.39, p=0.18$ & $-0.36, p=0.04$ \\
\cline { 2 - 6 } & Diastolic Pressure & $-0.17, p=0.41$ & $0.04, p=0.83$ & $-0.51, p=0.07$ & $-0.43, p<0.001$ \\
\cline { 2 - 6 } $\begin{array}{c}\text { Pearson } \\
\text { Correlation }\end{array}$ & Mean Arterial Pressure & $-0.39, p=0.85$ & $-0.08, p=0.69$ & $-0.46, p=0.11$ & $-0.48, p<0.001$ \\
\cline { 2 - 6 } & Temperature & $-0.08, p=0.70$ & $0.11, p=0.18$ & $0.22, p=0.45$ & $-0.19, p=0.36$ \\
\cline { 2 - 6 } & Shock Index & $-0.12, p=0.55$ & $0.21, p=0.32$ & $0.44, p=0.13$ & $0.59, p<0.001$ \\
\cline { 2 - 6 } & Respiratory Rate & $0.02, p=0.92$ & $-0.54, p<0.01$ & $0.56, p=0.04$ & $0.27, p=0.31$ \\
\hline
\end{tabular}




\section{DISCUSSION}

Preoperative vital signs correlated better than vital signs taken in emergency room. Proper fluid resuscitation done before surgery may be the underlying cause. We mainly focused on the vital signs taken at emergency department as preoperative vital signs were taken in operating room after the decision for surgery was made. HR, SBP and SI correlated better among all the vital signs. However none of the vital signs showed strong correlation with the amount of hemoperitoneum.

Our study showed statistically significant positive correlation between the heart rate and amount of hemoperitoneum $(\mathrm{r}=0.48, \mathrm{p}<0.001)$. Similarly significant negative correlation was observed between SBP and hemoperitoneum $(\mathrm{r}=-0.41, \mathrm{p}=0.001)$. However both of these correlations were considered weak. Only 19 of 36 patents with hemoperitoneum $\geq 750 \mathrm{ml}$ had $H R \geq 100$ beats/min and 8 patients had $\mathrm{SBP} \leq 90 \mathrm{mmHg}$. This finding was consistent with the study done by Birkhahn on 52 patents with reported correlation for HR, SBP and SI as 0.5, -0.34 and 0.69 respectively. ${ }^{8}$ WY Wong et.al showed even weaker correlation. ${ }^{9}$

The quantity of hemoperitoneum didn't correlate with the observed hemodynamic response. Compared to the study done by Hick et al. the reported association between the tachycardia and hypotension was observed in $37 \%$ of cases, ${ }^{7}$ our study showed even poor association (9 patients i.e. $14.75 \%$ of the cases). Similar observation was seen in research done by N. Mathlouthi et al where only 2 cases of hypotension and tachycardia was seen with the amount of hemoperitoneum above $1280 \mathrm{ml}^{10}$

Significant blood loss can occur even if the heart rate was normal. Case series reported by Charles Gallaher et al showed that patients had normal heart rate despite of massive intraperitoneal blood loss about 4 liters. ${ }^{11}$ In our study Among 38 patients who had $\mathrm{HR}<100$ beats/min, 13 patients had hemoperitoneum $\geq 750-1500 \mathrm{ml}$ and 5 patients had significant hemoperitoneum more than $1500 \mathrm{ml}$. This result was similar to various past studies.9, 10, 12 Therefore absence of tachycardia and hypotension should not mask the presence of ongoing hemoperitoneum and alter the management.

Most of the parameters performed well when the amount of hemoperitoneum was more than $1500 \mathrm{ml}$. However none of the vitals showed strong correlation. Among them SI showed better correlation of 0.718 similar to the study done by Birkhahn et al. ( $r=0.95)$ in cases with the larger amount of bleeding $>1000 \mathrm{ml} .^{8}$

The small number of study group was one of the limitations of our study. Preoperative fluid resuscitation done at emergency department and operating room could affect the clinical parameters. The amount of blood loss estimation during surgery is usually made as in round figure which could affect the actual amount of hemoperitoneum

Failure to recognize the association of hemoperitoneum with vital signs can cause serious maternal complications. Fortunately there were no maternal death reported. All the patients were treated timely with urgent surgical interventions that lead to better recovery rate and helped in preserving future fertility and maintain their reproductive life.

\section{CONCLUSIONS}

None of the vital signs showed strong correlation with the amount of hemoperitoneum. The absence of tachycardia and hypotension didn't rule out significant amount of hemoperitoneum. If decision for surgical interventions were made based on hemodynamic instability, most of the patients would have been over-diagnosed and/ or over-treated. Vital signs alone cannot be 
used for predicting ruptured ectopic pregnancy and ongoing blood loss. Early diagnosis and immediate management should be done because patient may be bleeding internally even with normal vital signs. Active monitoring of

\section{REFERENCES}

1. Taran FA, Kagan KO, Hübner $M$, Hoopmann M, Wallwiener D, Brucker S. The Diagnosis and Treatment of Ectopic Pregnancy. Deutsches Arzteblatt international. 2015;112(41):693-703; quiz 4-5.

2. Corrigan KJ, Kowalzyk DR. Ectopic ovarian pregnancy in a second-trimester patient. Am J Emerg Med. 2007;25(9):1085. e3-4.

3. Barnhart KT. Clinical practice. Ectopic pregnancy.N Engl J Med. 2009;361(4):37987.

4. Hooper N, Armstrong TJ. Hemorrhagic Shock. StatPearls. Treasure Island (FL): StatPearls Publishing Copyright (C) 2021, StatPearls Publishing LLC.; 2021.

5. Onah HE, Oguanuo TC, Mgbor SO. An evaluation of the shock index in predicting ruptured ectopic pregnancy. J Obstet Gynaecol. 2006;26(5):445-7.

6. Abbott J, Emmans LS, Lowenstein SR. Ectopic pregnancy: ten common pitfalls in diagnosis. Am J Emerg Med. 1990;8(6):51522.

7. Hick JL, Rodgerson JD, Heegaard WG, Sterner S. Vital signs fail to correlate with hemoperitoneum from ruptured vital signs combined with pelvic ultrasound and laparoscopy can be considered for making early diagnosis to prevent serious complications related to ruptured ectopic pregnancy.

ectopic pregnancy. Am J Emerg Med. 2001;19(6):488-91.

8. Birkhahn RH, Gaeta TJ, Van Deusen SK, Tloczkowski J. The ability of traditional vital signs and shock index to identify ruptured ectopic pregnancy. Am J Obstet Gynecol. 2003;189(5):1293-6.

9. Wong W, Tsui K, Tang Y. How Useful are Vital Signs in Identifying Patient with Ruptured Ectopic Pregnancy? A Retrospective Correlation Study. Hong Kong J Emerg Med. 2011;18(3):155-60.

10. Mathlouthi N, Ghodbane I, Slimani O, Ben Temime R, Makhlouf T, Attia L, et al. Correlation between vital signs and hemoperitoneum in ruptured ectopic pregnancy. Tunis Med. 2012;90(11):784-8.

11. Gallaher C, Tahmasebi F, Sayasneh A, Mehra G. Spontaneous Heterotopic Pregnancy Associated with Massive Intraperitoneal Haemorrhage and a Normal Heart Rate, Illustrating the Concept of Relative Bradycardia. Case Reports in Obstetrics and Gynecology. 2019;2019:2893149.

12. Somers MP, Spears M, Maynard AS, Syverud SA. Ruptured heterotopic pregnancy presenting with relative bradycardia in a woman not receiving reproductive assistance. Ann Emerg Med. 2004;43(3):382-5.

Citation: Chhetri P, Pathak P, Shrestha BK, Shrestha R, Acharya M, Shrestha S. Correlation Between the Vital Signs and Amount of Hemoperitoneum in Ruptured Ectopic Pregnancy. JCMS Nepal. 2021; 17(3); 203-7. 